\title{
Competencies in Mathematical Modelling Tasks: An Error Analysis
}

\author{
Hanti Kotze ${ }^{1 *}$ \\ ${ }^{1}$ University of Johannesburg, Johannesburg, SOUTH AFRICA
}

Received 23 January 2018 - Revised 6 April 2018 - Accepted 1 May 2018

\begin{abstract}
This paper aimed to investigate the type of modelling task that may elicit competencies that are more aligned with demands from the biomedical technology industry. The inquiry identified strengths and weaknesses in students' modelling competencies by analysing errors in two types of modelling tasks: atomistic and holistic. By using subtasks, errors could be identified according to the Newman error categories and compared with six modelling competencies according to the framework of Blum and Leiß. First-year biomedical technology students at a South African university made more errors in interpreting, validating and presenting, these being modelling competencies required to convert mathematical results to real-world results. The findings indicated that competencies embedded in atomistic tasks are more relevant to workplace demands in the local setting than those elicited in holistic modelling tasks. The implications for classroom practices are discussed.
\end{abstract}

Keywords: biomedical technology, mathematical modelling, error analysis, atomistic modelling, holistic modelling

\section{INTRODUCTION}

Mathematics is embedded in everyday phenomena but often remains isolated and unconnected with the real world. Contextually rich problems offer learning opportunities that allow students to connect the world of mathematics with real life. Contexts not only suggest strategies for problem-solving but can be an avenue to develop diversified skills. Schoenfeld (2001) warned that when skills are isolated from contexts, they are destined to be without meaning and purpose. For Freudenthal (1991, p. 75), contexts are "domains of reality disclosed to the learner in order to be mathematised". Reality is entrenched in contexts that relate to real life and should not only be pursued at the end of a study unit when mathematical content must be 'applied' (Van den Heuvel-Panhuizen, 2005). Instead, reality can be a rich source for learning and applying mathematics. Early experiences in which first-year students engage in real-world applications of mathematics can instill an appreciation of mathematics as an enviable tool in the bioengineering field.

New innovations and technological advancements, coupled with a greater awareness of the benefits of a healthy lifestyle, create a demand for different knowledge and skills in the biomedical technology industry (Magjarevic, Lackovic, Bliznakov, \& Pallikarakis, 2010). This industry-driven mandate requires innovative models of learning. Besides traditional approaches, learning should include: authentic tasks (Harris, Bransford, \& Brophy, 2002); problem-oriented learning (Magjarevic et al., 2010); information and communication technology (Mantas, Ammenwerth, Demiris et al., 2010); and small-group collaborations (Khan, Desjardins, Reba, Breazel, \& Viktorova, 2013) to enhance problem-solving and decision-making competencies (Huang, 2007). In South Africa (SA), there is scant research on the competencies needed in the biomedical sciences and the specific contribution from the Mathematics discipline.

The mathematics curriculum for biomedical students at UJ is to a large extent based on "contrived" word problems instead of genuine real-world problems (Gravemeijer, Stephan, Julie, Lin, \& Ohtani, 2017, p. 110). However, the overarching aim of the biomedical technology programme at the University of Johannesburg (UJ) is to train students to perform laboratory tests on human body fluids including blood, urine, body tissue and bone marrow (UJ, 2017). Using sophisticated procedures and equipment, biomedical technologists have to analyse data

(C) 2018 by the authors; licensee Modestum Ltd., UK. This article is an open access article distributed under the terms and conditions of the Creative Commons Attribution License (http://creativecommons.org/licenses/by/4.0/). \hantik@uj.ac.za (*Correspondence) 


\section{Contribution of this paper to the literature}

- Students are exposed to contextualised real-world problems for the first time to elicit mathematical competencies more in line with workplace skills.

- Modelling tasks were divided into subtasks, each eliciting specific modelling competencies.

- Error analysis revealed that atomistic modelling tasks attracted less errors in competencies embedded in the early phases of the modelling cycle.

samples in a laboratory with mathematical precision and accuracy; these include tests to determine blood types, drug levels and identification of bacterial or viral infections. Furthermore, the interpretation of test results must be precise and reliable. Reports that summarise test results must be scientifically accurate and are vital to medical practitioners who will base their diagnoses and subsequent treatments of patients on these reports. To this end, Humphrey, Coté, Walton, Meininger, and Laine (2005) acknowledged the benefits of a mathematical modelling approach in biomedical sciences: students can be exposed to the collection, analysis and interpretation of real-world data by working collaboratively. Alas, biomedical students at UJ are still unexposed to mathematical modelling and do not reap these potential benefits.

This apparent gap signaled the need for a dynamic interplay between mathematics as core discipline in the biomedical sciences and suitable problem-solving activities with embedded industry-based competencies. The overarching aim of this research was to investigate the type of modelling task that may be aligned with industryimposed competencies as alluded to above. The inquiry also necessitated insight into the types of errors made in different types of modelling tasks. The research was thus motivated by a desire to inform a pedagogy that could strike a balance between curricular imperatives and industry requirements.

\section{BACKGROUND}

Biomedical technology students register for a semester module in mathematics during their first year of study at UJ. Although the teaching and learning style remained largely traditional, Kotze, Jacobs, and Spangenberg (2015) reported that students in a pilot study at UJ were enthusiastic to learn in a mathematical modelling environment that offered greater articulation of skills in biomedical contexts. Students who register for the biomedical technology programmes at UJ come from diverse geographic, socio-economic, cultural and academic backgrounds. UJ continues to attract students from across the African continent. For most students, English is a second or even third language. An entry requirement into the biomedical technology programme at UJ is proficiency in English, the language of instruction and learning.

In 2014, the use of tablets/laptops became compulsory in classroom teaching and learning at UJ. By 2015 when a pilot study was undertaken, it became evident that the broader availability of hand-held electronic devices created scope for modelling activities that utilise real-world data. A laissez-faire approach to the use of technology in the mathematics classroom also seemed to stimulate inquisitiveness among students. On one occasion, some students expressed their curiosity about theories that could explain the disappearance of Malaysia Airlines Flight 370. This discussion diverted to the mysterious Bermuda triangle which was subsequently used as inspiration for a modelling task.

\section{LITERATURE PERSPECTIVES}

Mathematical modelling is the process whereby a real-life phenomenon is translated into a mathematical problem with the aim to find a realistic solution for the real-world situation (Blum \& Leiß, 2007). Although these protagonists of a mathematical modelling approach advocated its implementation at all levels of mathematics education, mathematical modelling is still a novel undertaking for most students at UJ and indeed elsewhere. Often, classroom activities focus more on abstract mathematical concepts and principles with little regard for their applicability, usefulness and connections with real life.

The modelling cycle (Blum \& Leiß, 2007, p. 225) is shown in Figure 1. To transition from one phase of the modelling cycle to the next requires certain modelling competencies as indicated on the right in Figure 1. 


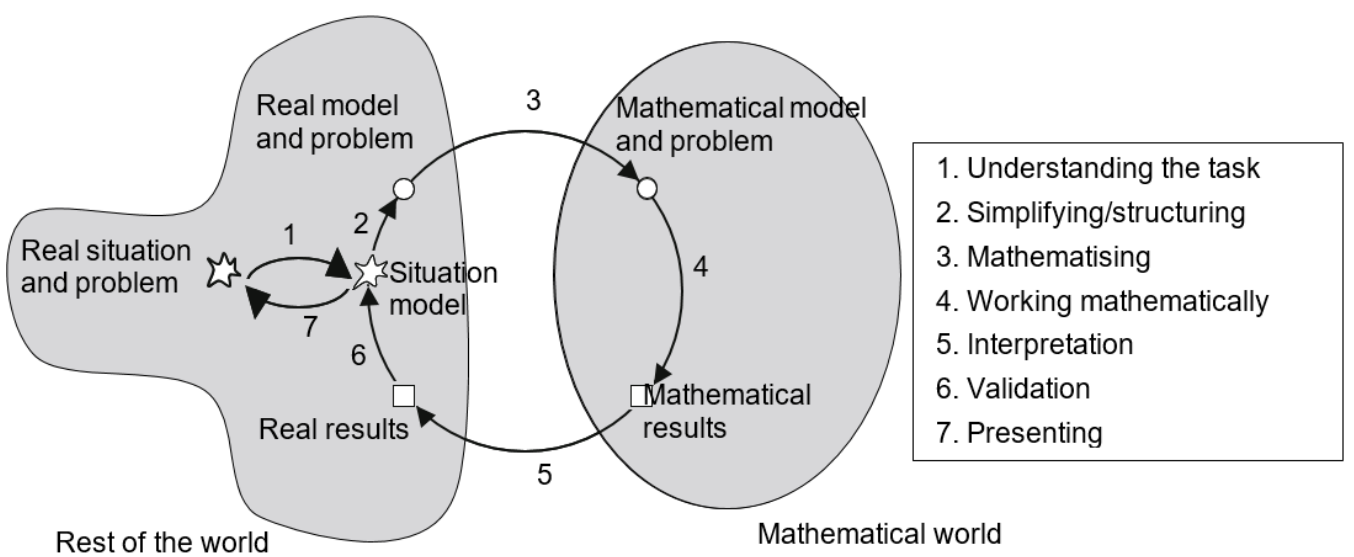

Figure 1. The mathematical modelling cycle (Blum \& Leiß, 2007, p. 225)

The modelling cycle originates in the physical world and relates to a real-world problem. A non-mathematical situation must be abstracted as a situation model; this helps to untangle and understand the reality-based problem. By simplifying the situation model, only relevant information is retained such that the situation model develops into an idealised real model. The real model is then translated into a mathematical model; Freudenthal (1991) labeled this process mathematising. In the next phase of the modelling process, the mathematical model must be manipulated mathematically. By working mathematically, all relevant mathematical domains and applicable skills, algorithms, processes and calculations are employed to produce a mathematical solution. The mathematical solution must then be interpreted in relation to the real model. To ensure that the mathematical model make sense in real-world terms, the solution must be validated. It may be necessary to repeat the modelling cycle if the mathematical solution is in conflict with the real-world situation. The modelling process concludes with the presentation of results. As an indispensable component of the modelling process, contexts allow for greater flexibility in the modelling cycle and add an open-ended character to the modelling process (Freudenthal, 1991).

Mathematical tasks, situated in contexts that students can easily relate to, have the potential to enhance students' sense-making of problems (Wijaya, van den Heuvel-Panhuizen, Doorman, \& Robitzsch, 2014). Contextrich tasks can even be relatively simple problems, as long as contextual settings contribute to learning and a deeper understanding of concepts. Students are likely to show more interest in tasks with contexts that draw on their own everyday experiences and curiosities (Wijaya et al., 2014). Contexts can be created by way of stories, illustrations, pictures and maps. Contextually rich settings can provide information, serve as a problem-solving stimulus, elicit model-building and support the validation of processes and solutions. Blomhøj and Jensen (2003) differentiated between two types of modelling: holistic modelling and atomistic modelling. In a holistic approach, students work through all modelling phases (Figure 1) but in an atomistic approach, only certain modelling phases are prioritised. Although it may be tempting to endorse only the atomistic approach due to its resemblance to traditional classroom strategies, Blomhøj and Jensen (2003) argued that these two approaches contribute in different ways to the modelling agenda.

Van den Heuvel-Panhuizen (2005) distinguished between contextually rich problems - where contexts should be mathematised - and word problems - where contexts do not matter. Newman (1977) identified five categories of errors to analyse students' difficulties when solving word problems; these are reading, comprehension, transformation, mathematical processes and encoding. Wijaya et al. (2014) pointed to remarkable similarities between the Newman error categories - associated with word problems - and errors made in the modelling processes as described by Blum and Leiß (2007). According to Wijaya et al. (2014), difficulties in context-rich modelling tasks relate to four competencies, namely, understanding, translating the real-world situation into a mathematical problem, working mathematically and interpreting the mathematical solution in real-world terms. Arguably, reading is part of understanding and therefore, Newman's reading and comprehension categories can be merged (Wijaya et al., 2014). The studies of Newman (1977), involving 11-13 year-old Australian students and that of Wijaya et al. (2014), involving 14-18 year-old Indonesian students, revealed similar results: low-performing students experienced difficulties with understanding and translating word problems or modelling tasks. Consequently, students in these two studies struggled to progress to the phase where mathematical work must be performed. Taking heed of these outcomes, this study investigated errors made by biomedical technology students in atomistic and holistic modelling tasks. The following research questions are posed: Which competencies attract the most errors in an atomistic modelling task? What are the differences between error trends in atomistic and holistic modelling tasks? 


\section{RESEARCH DESIGN AND METHODOLOGY}

Supported by a contextualist world view (Schraw, 2013), this study is predicated on knowledge that is not only applicable to real-world contexts, but is acquired from settings where new facts can collectively be debated. Within this paradigm, lecturers act as facilitators to promote learning experiences wherein students can negotiate a "consensual reality within a specific context" (Schraw, 2013, p. 3). Lave (1996, p. 155) considered the practices of tailor apprentices in Liberia and law students in Egypt to be grounded on "learning as [a] socially situated activity". In other words, informal but contextually rich practices as encountered in daily life characterise all learning activities.

The participants in this study were a 50-strong cohort of first-year biomedical technology students at UJ. The demographics of the cohort revealed more female students (56\%), representation from five of the nine provinces in SA while two students came from other African countries. Students' ages ranged between 18 and 21 years and $87 \%$ of the cohort's home language was not English. For the modelling tasks, students were divided into ten groups of four to six students per group. Using recent semester test scores, each group included low, middle and high performers. With this group structure, it was hoped that low performers would be more inspired, and high performers would demonstrate and articulate their 'better' abilities. This was students' first exposure to a mathematical modelling approach.

Over the course of a semester, students were exposed to four mathematical modelling tasks. For each of the four tasks, a newspaper article was sourced that described a real-world problem. Task 1 was based on a community project in the Eastern Cape province of SA. The narrative described a project wherein children could exchange recyclables for 'Moolas' (a made-up currency). In turn, Moolas could be accumulated over time to be exchanged for 'treasures' such as stationary and food items. The task challenged students to design a poster that could be used as a guide for trading different types of recyclables (e.g. plastic, glass) for different types of 'treasures'. In Task 2, students had to construct a realistic three-month budget with which to create a garden with plants, trees and lawn. The budget, to be spend at a Garden center, also had to accommodate discounts on certain items during certain months. Task 3 related to the mysterious disappearance of boats and airplanes over the Bermuda Triangle and was analysed in this study. Task 4 described an experiment on Mount Everest that related to the oxygen levels in human blood at different altitudes as reported in Kotze et al. (2015).

All tasks were designed to elicit mathematical modelling competencies as suggested by Blum and Leiß (2007). Using this framework, the modelling process could be critically analysed by identifying errors in each phase of the modelling cycle. Also, the framework helped to detect whether required competencies were attained in each transition. Galbraith and Stillman (2006) suggested the use of subtasks to help trace performance at different phases of the modelling process. It was important to anticipate students' approaches to the task and the types of errors that could be made. In designing the tasks, it was also necessary to ensure that all relevant mathematical knowledge and technological skills required to perform the task were already considered in prior study units.

Each custom-designed task was completed within a scheduled 90-minute tutorial period. Task 3 was dubbed the Bermuda Triangle task and this triangle is shown in Figure 2. A narrative described the enigmatic disappearance of aircraft and ships over the triangle (Appendix A). To assist students with the progression through the modelling cycle, the task was delineated into five subtasks. Although the model for the area of the triangle was given, it still had to be analysed and interpreted in terms of the real-world contexts. Students had to use hand-held technology to source the global positioning system (GPS) coordinates of the vertices of the Bermuda triangle. In effect, each different set of GPS coordinates would result in a different area. This freedom of choice facilitated the open-endedness of the modelling task. 


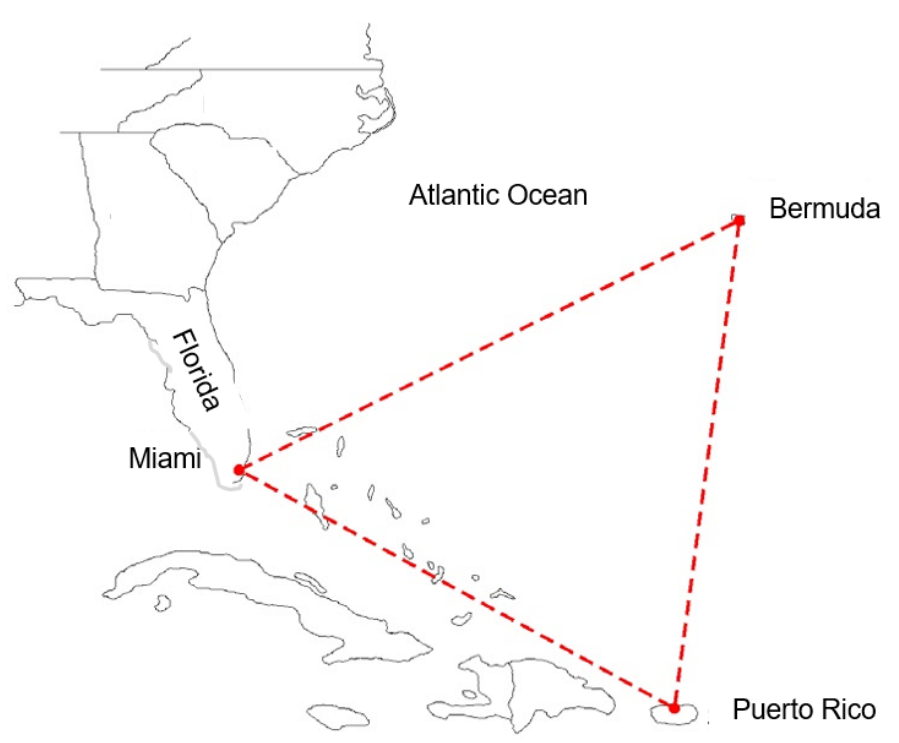

Figure 2. The Bermuda Triangle map

All students had the opportunity to participate in the modelling task. To encourage students' attendance and participation, the task contributed to the semester mark. Each group submitted a completed worksheet which was assessed by the researcher and moderated by another subject expert. The inter-rater reliability of the task was measured with Cohen's kappa $(\kappa=0.81)$. Stoddart, Abrams, Gasper, and Canaday (2000) proposed that kappa values between $0.21-0.40$ reveal poor agreement between raters but values between $0.41-0.75$ indicate to a moderate to good agreement. As such, the agreement between raters for the Bermuda triangle task was excellent. A pilot study was conducted the previous year which confirmed the content validity of the task.

\section{DATA ANALYSIS}

Group documents were analysed with content analysis. Following Wijaya et al. (2014), Table 1 aligns the Newman (1977) error categories in column one with the mathematical modelling competencies as described by Blum and Leiß (2007) in column two. However, mathematising and interpreting were further sub-divided to allow for more nuanced analyses of these two important but difficult competencies in the modelling cycle (Blum \& Leiß, 2007). This brings the number of modelling competencies in column two to six. In scoring the task, all six modelling competencies were considered equally important. For each competency, a zero score was awarded for an inappropriate response or a score of one for a relevant response; therefore, the maximum score that could be awarded for the task was six. Since there were ten groups, the total number of possible errors made in the task amounted to 60. Overall, 21 errors were recorded in the task. The most common errors appear in the third column of Table 1. The last column reflects the specific subtask related to the Newman error category, modelling competencies and related errors. 
Table 1. Newman's error categories, modelling competencies and typical errors in the Bermuda Triangle task

\begin{tabular}{|c|c|c|c|}
\hline $\begin{array}{l}\text { Newman's error } \\
\text { categories }\end{array}$ & $\begin{array}{l}\text { Modelling competencies } \\
\text { (\% errors) }\end{array}$ & Errors & Subtask \\
\hline Comprehension & Understanding (0\%) & $\begin{array}{l}\text { - No errors were made as all groups could fully } \\
\text { understand the task and source omitted data (GPS } \\
\text { coordinates) }\end{array}$ & $\begin{array}{l}\text { a. Source the } \\
\text { omitted GPS data by } \\
\text { using technology }\end{array}$ \\
\hline \multirow[t]{2}{*}{ Transformation } & $\begin{array}{l}\text { Mathematising_1 } \\
\text { (GPS coordinates) (23.8\%) }\end{array}$ & $\begin{array}{l}\text { - Incorrect conversion of GPS coordinates from degrees } \\
\text { minutes and seconds (DMS), to decimal degrees (DD) } \\
\text { - Incorrect positioning of GPS coordinates on vertices of } \\
\text { triangle } \\
\text { - Unable to associate North and East with positive } \\
\text { coordinates and South and West with negative } \\
\text { coordinates }\end{array}$ & $\begin{array}{l}\text { b. Convert GPS } \\
\text { coordinates from } \\
\text { DMS to DD }\end{array}$ \\
\hline & $\begin{array}{l}\text { Mathematising_2 (set up } \\
\text { determinant) }(0 \%)\end{array}$ & $\begin{array}{l}\text { No errors were made in representing relevant vertices } \\
\text { of the triangle in order to set up the appropriate } \\
\text { determinant }\end{array}$ & \multirow{2}{*}{$\begin{array}{l}\text { c. Calculate the area } \\
\text { - of the triangle using } \\
\text { the given formula }\end{array}$} \\
\hline Process skills & $\begin{array}{l}\text { Working mathematically } \\
(9.5 \%)\end{array}$ & $\begin{array}{l}\text { - Using wrong co-factor expansion in the evaluation of } \\
\text { the determinant } \\
\text { - Calculation mistakes in evaluating determinant }\end{array}$ & \\
\hline \multirow[b]{2}{*}{ Encoding } & $\begin{array}{l}\text { Interpreting } \\
(23.8 \%)\end{array}$ & $\begin{array}{l}\text { - Mistaking } \pm \text { signs in given determinant model for } \pm \\
\text { signs associated with longitude or latitude } \\
\text { - Confusing } \pm \text { sign in given model with } \pm \sqrt{ } \text { (as in } \\
\text { taking the square root) }\end{array}$ & $\begin{array}{l}\text { d. Explain the } \\
\text { meaning of } \pm \text { sign in } \\
\text { given formula }\end{array}$ \\
\hline & $\begin{array}{l}\text { Validating and presenting } \\
(42.9 \%)\end{array}$ & $\begin{array}{l}\text { - Presenting area as a negative value } \\
\text { - Unrealistic answer given in } \mathrm{km} \text { instead of } \mathrm{km}^{2} \\
\text { - Unable to judge correctness of Bermuda triangle area } \\
\text { - Presenting area in degrees (without converting to } \mathrm{km}^{2} \text { ) }\end{array}$ & $\begin{array}{l}\text { e. Convert the } \\
\text { calculated area of } \\
\text { the triangle from } \\
\text { degrees to } \mathrm{km}^{2} \text { using } \\
1^{\circ}=111.701 \mathrm{~km}\end{array}$ \\
\hline
\end{tabular}

The task was firstly analysed according to the modelling competencies of Blum and Leiß (2007) where errors were not allowed to accumulate. For example, a wrong conversion of the GPS coordinates was not again penalised in follow-up calculations. The task was secondly analysed according to Newman's (1977) error categories.

Analysing the task according to competencies suggested by Blum and Leiß (2007), the first transition evoked understanding. Students had to read the narrative and understand what to do in terms of the contextual setting of the task. The task involving the Bermuda triangle map (Figure 2) probed students to visualise the task and aimed to stimulate a sense of familiarity with the real-world contexts of the task. The subtasks (Appendix A) were designed to stimulate understanding and help students to structure, simplify and delineate processes (Blum \& Leiß, 2007). Since all groups could successfully source the omitted data (GPS coordinates) with technology and acquired a full understanding of the task, no errors were recorded in understanding. In the modelling transition that elicited mathematising for the first time, students had to apply their prior knowledge of longitudes, latitudes and GPS coordinates to convert their real-world data from degrees, minutes and seconds (DMS) to decimal degrees (DD). Analogous to Cartesian coordinates, a point on the longitude-latitude grid is positive if it lies North of the Equator (the latter represents an East-West axis or $0^{\circ}$ latitude); alternatively, a point is negative if it lies South of the Equator. Similarly, a point is positive when it lies East of the Prime Meridian (representing a North-South axis or $0^{\circ}$ longitude) and negative if it lies West of the Prime Meridian. For example, the DMS coordinates $\left(32^{\circ} 18^{\prime} 28,08^{\prime \prime} \mathrm{N}\right.$; $\left.64^{\circ} 45^{\prime} 1,8^{\prime \prime} \mathrm{W}\right)$ of St George in Bermuda had to be converted to DD coordinates $\left(32,3078^{\circ} ;-64,7505^{\circ}\right)$. Altogether, $23.8 \%$ of all errors were made in the first instance of mathematising, that is, mathematising of the real-world data. On the contrary, no errors were recorded in the second round of mathematising. This means that all groups could accurately present their assumed GPS coordinates in terms of the given determinant - which represented the mathematical model to calculate the area of the Bermuda triangle. Working mathematically seemed to be an easy part of the task. Procedural errors in this competency amounted to $9.5 \%$ of all errors made in the task; these included calculation mistakes and using incorrect co-factor expansions to evaluate the determinant. Errors in interpreting the solution were also $23.8 \%$ of all errors made; thus, the second highest alongside the first mathematising process. The plus-minus sign in the determinant was incorrectly interpreted by five groups. Group 8 spontaneously associated the plus-minus sign with the quadratic formula - this perhaps being the only instance where students have encountered this dual sign before - and trustingly computed the square root of the area. Three other groups confused this plus-minus sign with signs associated with the directions North, East, South and West. Unexpectedly, the validating and presenting competencies amassed most errors (42.9\%). Since the Equator is divided into 360 degrees on the longitudinal axis, each decimal degree on the equator represents approximately 111,701 km. A conversion was therefore required to present the area of the Bermuda triangle in square kilometers. Most groups 


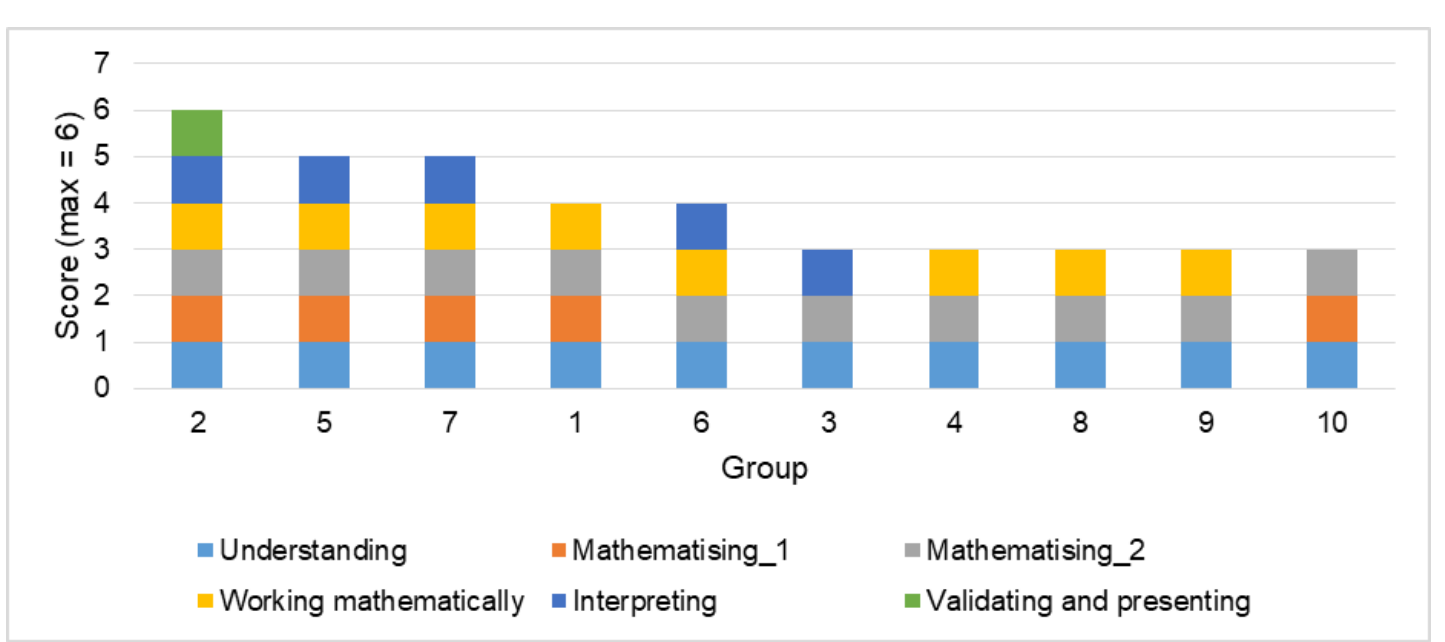

Figure 3. Percentage correct responses of ten groups

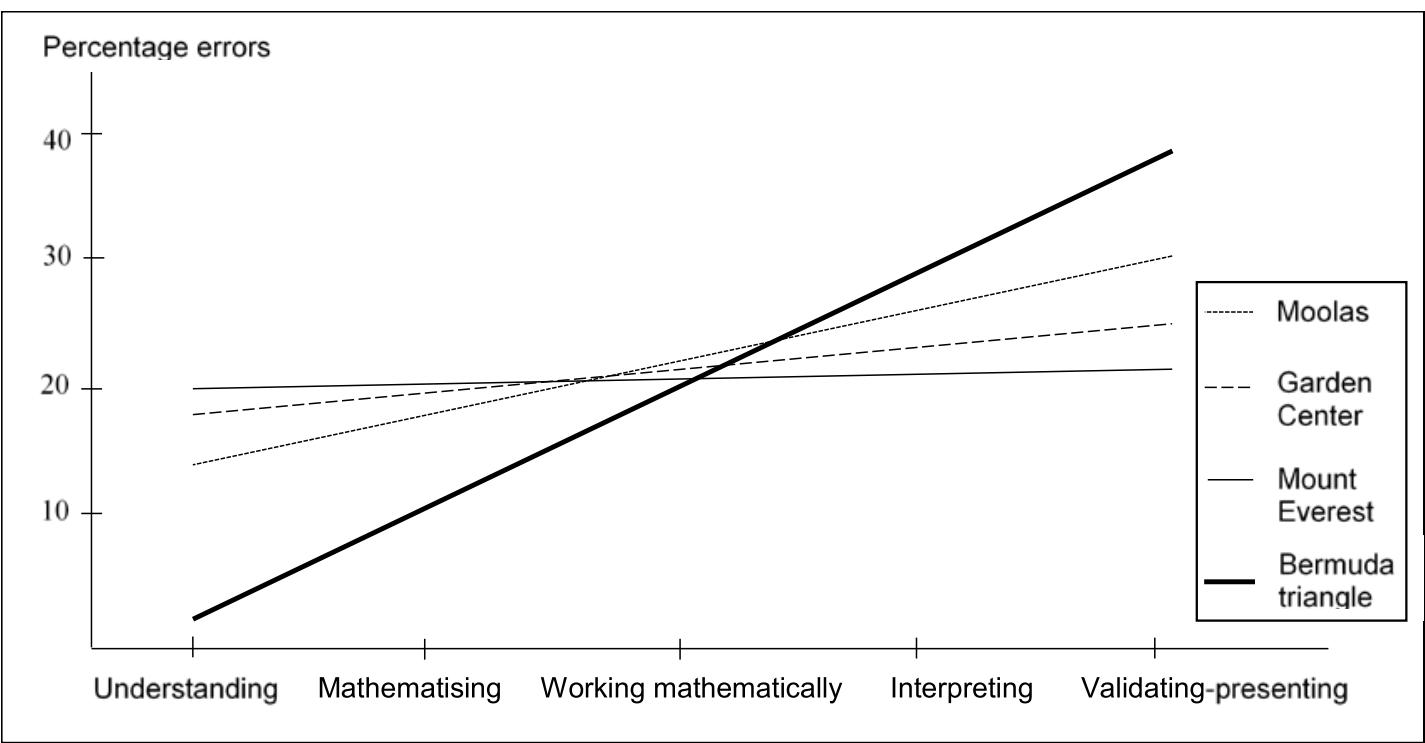

Figure 4. Trendlines showing percentage errors in the four modelling tasks

erred by multiplying the area by $111,701 \mathrm{~km}$ instead of $(111,701 \mathrm{~km})^{2}$. In a former study unit, students were fluent with comparable conversions such as from $\mathrm{m} / \mathrm{s}$ to $\mathrm{km} / \mathrm{h}$. If the interpreting step is combined with the validating and presenting steps, this collective category (labelled Encoding, according to Newman, 1977) accounted for $66.7 \%$ of all errors made in the task. Figure 3 shows the correct responses in each modelling competency for each group. Only Group 2 obtained the maximum score (six) while five groups succeeded in only three of the modelling competencies.

Overall, the four modelling tasks differed substantially in terms of the competencies which attracted most errors. While the Bermuda triangle task was nearly free from errors in the first three competencies embedded in the modelling cycle, competency errors in the other three tasks (Moolas, Garden center and Mount Everest) were mostly stable across all the modelling phases. In order to compare the trend in errors across all four tasks, the other three tasks were also analysed according to five modelling competencies namely understanding, mathematising, working mathematically, interpreting and validating-presenting. Figure 4 presents the trendlines of the four tasks and shows the percentage errors in the five modelling competencies. The trendlines suggest that errors in the Moolas, Garden center and Mount Everest tasks are mostly clustered about the 13-25\% error levels.

Interestingly, the trendline for the fourth task (Mount Everest) almost levels out into a flat line, meaning that errors in modelling competencies were constant across this task. In fact, the Mount Everest task attracted the least number of errors overall, which could indicate that students were getting more accustomed to the modelling approach. It could also be that this task, with its direct links to the biosciences (modelling oxygen levels in blood at 


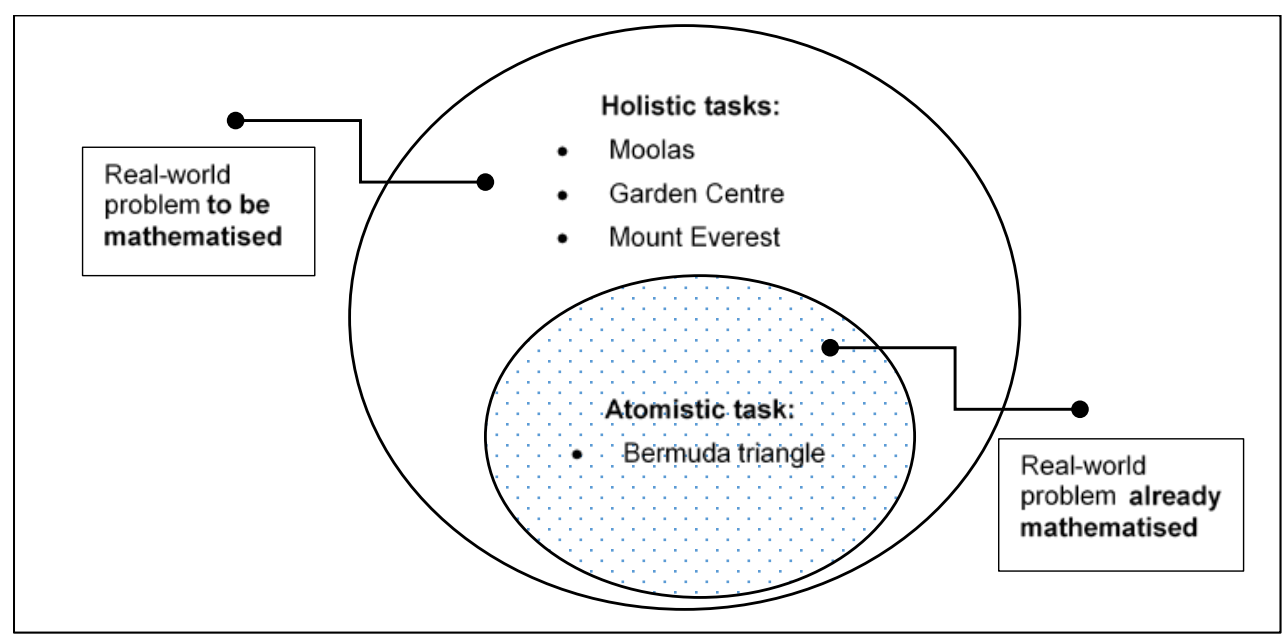

Figure 5. Holistic versus atomistic modelling tasks

different altitudes), allowed students to make better connections between mathematical symbols and real-life contexts.

In contrast, the trendline of the Bermuda triangle in Figure 4 confirms that few errors were made in understanding, mathematising and working mathematically while most errors occurred in the competencies of interpreting and validating-presenting (compare Table 1). The reason for this contrasting trend could possibly lie in the nature of the tasks. The main difference between the four modelling tasks in this study is that the mathematical model was provided in the Bermuda triangle task, meaning that the actual mathematising transition as suggested in Figure 1 was largely bypassed; therefore this task can be classified as atomistic. In the other three tasks, students had to mathematise the real-world problem and construct a mathematical model themselves; these three tasks were therefore holistic (Blomhøj \& Jensen, 2003). Figure 5 illustrates the comprehensive nature of the other three holistic tasks - which involved all modelling phases - while as an atomistic task, the Bermuda triangle task can be regarded as a subset of the holistic approach since mathematising was avoided.

\section{DISCUSSION}

According to Schoenfeld (2001), mathematics in contexts relate to the use of ordinary tools and skills in new contexts. The Bermuda triangle contexts encouraged students to source missing data, mathematise global coordinates of real-world places and transfer data to an unfamiliar model (area of the triangle). Students had to exhibit ownership of prerequisite knowledge and technological skills to make sense of the task. The task commanded various mathematical concepts - areas, determinants, coordinates, conversions between DMS and DD, the dual meaning of the plus-minus sign in the given model and conversion from DD to $\mathrm{km}^{2}-$ to be integrated into new contexts.

Results indicated that students could fully understand the intention of the task which eased the way for five groups to mathematise the real-world data without errors. On the one hand, it was possible that the earlier impromptu conversation about the missing Malaysian flight 370 - and widely publicised media coverage of subsequent search efforts by the international community - helped to promote a deeper understanding of the task. Specifically, media reports captured the extent of the search area which possibly helped students to picture distances travelled in an airplane, though it is likely that most students would not been in an airplane before. On the other hand, since the detailed worksheet (Appendix A) was not handed out immediately, additional time was allowed for informal group discussions which may have helped students to intuitively understand the goal of the task. Students would typically communicate in their native tongue during these discussions. However, many English terms are not necessarily easily translated, and are often adopted in a mode mixed with African languages; for example, concepts such as 'iPad', 'triangle', 'area' and 'GPS' remained untranslated. This was the third modelling task and students seemed to be more familiar with their group dynamics. By now, it was practice for students to work in their respective groups, even during traditional lectures. Throughout the Bermuda triangle task, the classroom mood was notably informal, talkative and animated.

The given mathematical model for the area of a triangle was a novelty; yet all groups could correctly transfer their mathematised data to the model. Mathematical work was performed with prudence and errors were only observed in Group 3. Up to this point in the task, a mere 33\% of the total amount of errors were noted. Most likely, this acclaimed success can be ascribed to the design of subtasks that had a scaffolding impact on students' 
modelling processes; in particular the modelling competencies of understanding, mathematising and working mathematically. The error 'slips' that would occasionally occur due to negligence could probably be resolved through the collective input of the group. In this sense, the heterogeneous composition of groups might have contributed to these gains. As a result, students were mostly successful in applying relevant mathematical concepts and coordinating mathematical tools to the contexts of the Bermuda triangle (Schoenfeld, 2001).

This outcome is contrary to the findings of Wijaya et al. (2014) who reported that most errors were made in understanding and mathematising. However, the study of Wijaya et al. indicated that fewer errors were made in working mathematically and interpreting the solution. A major concern was students' inability to take the contexts of the Bermuda triangle problem into account in the final phases of the task which had to be supported by interpreting, validating and presenting. This unexpected finding is in contrast with Newman (1977) and Wijaya et al. (2014) who found that younger children in their respective studies mostly encountered problems with the earlier phases of the modelling cycle. These differences may be due to the atomistic nature of the Bermuda triangle task and the specific structure of subtasks which elicited one modelling competency at a time.

Gainsburg (2013) believed that atomistic tasks may be desirable to underscore and lay the foundation to holistic modelling. By focusing on strategic modelling competencies in atomistic tasks, students can be prepared for more comprehensive modelling tasks. Gainsburg (2013) refers to an atomistic approach as learning to model piece-bypiece. As such, atomistic tasks can help with the development of specific modelling competencies. For biomedical technologists, the interpretation and validation of laboratory data that culminate in report-writing (presenting) are important modelling skills that can be learned through atomistic tasks. The Bermuda triangle task was atomistic by nature since the mathematical model (area formula, given as a determinant) was provided. Although mathematising was side-stepped, this task contributed in a different but arguably also important way: it presented opportunities to focus more on the critical and quantitative analysis of the given model, its real-world meaning, interpretation and ultimately, the usefulness of the mathematical concept at hand. Blomhøj and Jensen (2003) also believed that a holistic approach to mathematical modelling is indeed time-consuming and that students need ample time to adjust to a modelling environment. Another complication is that mathematising is widely regarded to be cognitively challenging. For biomedical technologists who have a high-school modelling deficiency and only one semester of university mathematics, the atomistic approach may be more suitable to attain competencies in line with workplace demands.

Arguably, the competencies embedded in the final phases of the Bermuda triangle task - interpreting, validating and presenting - required students to build up considerable understandings from symbols to reality. However, students struggled to coherently unite their mathematical work with real-world contexts. This finding also suggested that students were able to accurately calculate the area of a triangle but fell short of interpreting the symbolic significance thereof in the real world. One reason for this apparent divide between mathematics and reality may be that most students seemed to be reluctant - or perhaps unused - to reflect on contexts in order to 'find truth' in their answers. This reluctance may even suggest that interpreting, validating and reporting on the task, which accumulated $66.7 \%$ of errors, were not part of students' standard classroom repertoire. Classroom practices which rarely stimulate these modelling competencies where errors predominated, may induce difficulties to reason meaningfully about solutions. As Schoenfeld (2001, p. 53) pointedly stated, all that is often required of students is "to draw a box around the correct answer". Rightfully, there should be reservations whether the notion of area was truly contextualised given that most groups failed to present their answers in square units. Whereas students were more fluent with individual concepts - such as area and converting in-between different units - in earlier study topics, the same concepts, when intertwined into one task, could not be connected coherently. This failure is evidence that conceptual understanding and fluency in the earlier phases of the modelling cycle could not secure a real-world interpretation, validation and presentation of a real-world problem.

When the Bermuda triangle task was analysed according to the Newman (1977) error categories, errors were considered to be hierarchical and were allowed to accumulate from step to step (Wijaya et al., 2014). Per illustration, students in Group 3 used incorrect signs when they converted their GPS coordinates from DMS to DD; consequently, they obtained a negative area for the Bermuda triangle. This error was however 'fixed' in the next subtask when they correctly interpreted the plus-minus sign as a means to eliminate the negative value obtained for the area. This amendment is evidence that contexts were employed even though errors were made in previous steps. Even so, relatively few errors (39\%) were made in the Newman error categories of comprehension, transformation and process skills. It therefore seems that errors identified with the modelling framework of Blum and Leiß (2007) were consistent with the Newman analysis. Again, specific subtasks served as a diagnostic tool to identify weaknesses in specific Newman categories.

The modelling competencies of Blum and Leiß (2007) are considered to be more suitable to analyse a modelling task, which ultimately, is more concerned with a meaningful solution than with adequate procedural processes. Clearly, more research is needed to find a balance between atomistic and holistic modelling within specific educational and curricular constraints (Blomhøj \& Jensen, 2003). 


\title{
CONCLUSION
}

The aim of this article was to investigate the potential of different mathematical modelling tasks that could underscore competencies suitable to the biomedical industry. To this end, error types and trends were explored in both atomistic and holistic modelling tasks. By aligning subtasks with specific phases of the modelling cycle and embedded competencies, error analyses of modelling tasks could reveal students' strengths and weaknesses throughout the modelling cycle. Research question one was:

\section{Which competencies attract the most errors in an atomistic modelling task?}

The contextual setting of the Bermuda triangle task demonstrated that when students understand the meaning of real-world contexts, they are more likely to be successful to operate, transfer and model with real-world data. While the conversion from real-world data to mathematical symbols attracted minimal errors, most errors occurred in the reverse direction: converting mathematical results in a meaningful way to real world results. Students were mostly unsuccessful with the phases in the modelling cycle which elicited interpreting, validating and reporting. This deficiency may be an indication that these competencies do not receive the attention it deserves in traditional classroom practices. As such, mathematical results remained largely unconnected to the real world.

Research question two was:

What are the differences between error trends in atomistic and holistic modelling tasks?

When the atomistic task was compared with the holistic tasks, the most dominant errors in both types of tasks occurred with interpreting, validating and presenting. This means that in both types of tasks, students struggled most to convert mathematical results to reality. Furthermore, in the holistic tasks errors tended to be more equally distributed across all modelling competencies. This means that, even though the atomistic task side-stepped the initial phases of the modelling cycle - regarded to be a considerable cognitive barrier - difficulties were still more prevalent in the latter phases of the modelling cycle which probed competencies involving interpreting, validating and presenting of results.

The implications for practice are unambiguous. Biomedical technologists will need to interpret laboratory data, validate results and write reports, all of which are important modelling competencies which can be learned via atomistic modelling tasks. Students were unaccustomed to contextually rich tasks and need more opportunities to crisscross the divide between their own world and the formal world of mathematics. Available evidence of specific shortcomings coupled with target educational goals and workplace imperatives can guide the design of a more desirable classroom pedagogy. After all,

\begin{abstract}
errors are seen not only as natural, inevitable and [an] integral part of learning but are also regarded as valuable sources of information about the learning process; providing clues that researchers and teachers should take advantage of in order to uncover current students' knowledge and how they come to construct such knowledge" (Makonye, 2011, p. 19).
\end{abstract}

\section{LIMITATIONS AND RECOMMENDATIONS}

A limitation of the study was that only one of the modelling tasks was atomistic in nature. There is potential for future research to find a balance between atomistic and holistic modelling tasks. The sample was restricted to a relatively small cohort of 50 biomedical students studying towards a National Diploma in Biomedical Technology and can therefore not be generalised to all biomedical technology students. How students will respond to a task with a more local context may be an area for further investigation. As mathematical modelling is still in its infant shoes in SA, there is a need for further research on error analysis to help structure more suitable pedagogies for biomedical technology students who have to face a world of work with twenty-first-century demands.

\section{REFERENCES}

Blomhøj. M., \& Jensen, T. H. (2003). Developing mathematical modelling competence: conceptual clarification and educational planning. Teaching Mathematics and its Applications, 22(3), 123-140. https:/ / doi.org/10.1093/teamat/22.3.123

Blum, W., \& Leiß, D. (2007). How do students and teachers deal with modelling problems? In C. Haines, P. Galbraith, W. Blum, \& S. Kahn (Eds.), Mathematical modelling: Education, Engineering and Economics - ICTMA 12 (pp. 222-231). Chichester: Horwood Publishing. https:/ / doi.org/10.1533/9780857099419.5.221

Freudenthal, H. (1991). Revisiting mathematics education. Dordrecht: Kluwer Academic Publishers.

Gainsburg, J. (2013). Learning to model in engineering. Mathematical Thinking and Learning, 15(4), $259-290$. https:/ / doi.org/10.1080/10986065.2013.830947 
Galbraith, P., \& Stillman, G. (2006). A framework for identifying student blockages during transitions in the modelling process. ZDM Mathematics Education, 28(2), 143-162. https:/ / doi.org/10.1007/BF02655886

Gravemeijer, K., Stephan, M., Julie, C., Lin, F., \& Ohtani, M. (2017). What mathematics education may prepare students for the society of the future? International Journal of Science and Mathematics Education, 15, 105-123. https:/ / doi.org/10.1007/s10763-017-9814-6

Harris, T. R., Bransford, J. D., \& Brophy, S. P. (2002). Roles for learning sciences and learning technologies in biomedical engineering education: a review of recent advances. Annual Review of Biomedical Engineering, 4 , 29-48. https:/ / doi.org/10.1146/annurev.bioeng.4.091701.125502

Huang, Q. R. (2007). Competencies for graduate curricula in health, medical and biomedical informatics: a framework. Health Informatics Journal, 13(2), 89-103. https:/ / doi.org/10.1177/1460458207076465

Humphrey, J. D., Coté, G. L., Walton, J. R., Meininger, G. A., \& Laine, G. A. (2005). A new paradigm for graduate research and training in the biomedical sciences and engineering. Advances in Physiology Education, 29(2), 98102. https:// doi.org/10.1152/advan.00053.2004

Khan, T., Desjardins, J., Reba, M., Breazel, E., \& Viktorova, I. (2013). Quantitative methods in biomedical applications: creative inquiry and digital-learning environments to engage and mentor STEM students in mathematics. In J. Rychtár̆, R. Shivaji, S. Gupta, \& M. Chhetri (Eds.), Topics from the 8th annual UNCG regional mathematics and statistics conference, Springer Proceedings in Mathematics and Statistics 64 (pp. 15-24). New York: Springer. https:/ / doi.org/10.1007/978-1-4614-9332-7_3

Kotze, H., Jacobs, G., \& Spangenberg, E. (2015). Attitudes of biomedical technology students towards mathematical modelling. Proceedings of the ISTE International Conference on Mathematics, Science and Technology Education, 25 - 29 October, Mopani Camp, Kruger National Park, South Africa, 136-148.

Lave, J. (1996). Teaching, as learning, in practice. Mind, Culture, and Activity, 3(3), 149-164. https://doi.org/10.1207/s15327884mca0303_2

Magjarevic, R., Lackovic, I., Bliznakov, Z., \& Pallikarakis, N. (2010). Challenges of the biomedical engineering education in Europe. Proceedings of the 32nd Annual International Conference of the IEEE EMBS, Buenos Aires, Argentina, August 31 - September 4, 2959-2962. https:/ / doi.org/10.1109/IEMBS.2010.5626263

Makonye, J. P. (2011). Learner mathematical errors in introductory differential calculus tasks: a study of misconceptions in the senior school certificate examinations (PhD thesis), University of Johannesburg, Johannesburg, South Africa.

Mantas, J., Ammenwerth, E., Demiris, G., Hasman, A., Haux, R., Hersh, W., Hovenga, E., Lun, K. C., Marin, H. Martin-Sanchez, F., \& Wright, G. (2010). International Medical Informatics Association (IMIA) on education in health and medical informatics - 1st revision. Methods of Information in Medicine, 49(2), 105-120. https://doi.org/10.3414/ME5119

Newman, M. A. (1977). An analysis of sixth-grade pupils' errors on written mathematical tasks. Victorian Institute for Educational Research Bulletin, 39, 31-43.

Schoenfeld, A. (2001). Reflections on an impoverished education. In L.A. Steen (Ed.), Mathematics and democracy: the case for a quantitative literacy (pp. 49-54). National Council on Education and the Disciplines

Schraw, G. (2013). Conceptual integration and measurement of epistemological and ontological beliefs in educational research, Review article, Hindawi Publishing Corporation ISRN Education, Volume 2013, Article ID 327680. https:/ / doi.org/10.1155/2013/327680

Stoddart, T., Abrams, R., Gasper, E., \& Canaday, D. (2000). Concept maps as assessment in science inquiry learning - a report of methodology. International Journal of Science Education, 22(12), 1221-1246. https:/ / doi.org/10.1080/095006900750036235

University of Johannesburg (2017). Faculty of Science, Doornfontein campus, Rules and regulations for undergraduate programmes. Retrieved from www.uj.ac.za/science

Van den Heuvel-Panhuizen, M. (2005). The role of contexts in assessments. For the Learning of Mathematics, 25(2), 29.

Wijaya, A., van den Heuvel-Panhuizen, M., Doorman, M., \& Robitzsch, A. (2014). Difficulties in solving contextbased PISA mathematics tasks: an analysis of students' errors. The Mathematics Enthusiast, 11(3), 555-584. 


\section{APPENDIX A}

\section{The Bermuda Triangle Task}

Handout one (the narrative and map): The Bermuda triangle is a region of the north-western Atlantic Ocean in which a number of aircraft and surface vessels are alleged to have disappeared under mysterious circumstances, all of which fall beyond the boundaries of human error, pirates, equipment failure or natural disasters. Some writers attributed the disappearances of aircraft and boats to UFOs. This idea was used by Steven Spielberg for his science fiction film Close Encounters of the Third Kind, which features the lost Flight 19 as alien abductees. Others believed that the Bermuda Triangle is a wormhole (a gap in space and time). Plan a strategy to approximate the area of the Bermuda triangle.

Handout two (the worksheet):

a) Search for the GPS coordinates of St George in Bermuda, San Juan in Puerto Rico and Miami in Florida.

b) Convert these GPS coordinates to decimal degrees.

c) The area of a triangle with vertices $\left(x_{1}, y_{1}\right) ;\left(x_{2}, y_{2}\right)$ and $\left(x_{3}, y_{3}\right)$ is given as

$$
A= \pm \frac{1}{2}\left|\begin{array}{lll}
x_{1} & y_{1} & 1 \\
x_{2} & y_{2} & 1 \\
x_{3} & y_{3} & 1
\end{array}\right|
$$

Use this formula to calculate the area of the Bermuda triangle.

d) What do you think is the meaning of the plus/minus sign in the formula given in Question c?

e) Convert the area of the Bermuda triangle to square kilometers; assume 1 degree $=111,701 \mathrm{~km}$.

\section{http://www.ejmste.com}

